\title{
Nazarbayev Intellectual School Libraries: The Development of Functional Literacy and Reading Skills
}

\author{
Aida Agadil \\ Nazarbayev Intellectual Schools, Kazakhstan \\ Olga Salamakhina \\ Nazarbayev Intellectual school of Physics and Mathematics in Kokshetau, Kazakhstan \\ Gulmariyam Tubekbayeva \\ Nazarbayev Intellectual School of Chemistry and Biology in Kyzylorda, Kazakhstan
}

\begin{abstract}
Nazarbayev Intellectual Schools (NIS) are a testing site for piloting innovations in teaching and learning in Kazakhstan's formal education system. Fostering the development of multicultural, strongminded students is a key component of an NIS school, and the library certainly plays an important role in the formation and development of students. This article presents the practical knowledge of NIS librarians which was gained through such practices as the use of applied gaming methods to promote reading, the development of information and functional literacy, the development of research skills and the development of functional literacy.

School library activities should not have limitations; the school library is a center for reading, creativity and intellectual development. By using new methods, constantly improving and maintaining a friendly atmosphere, the school library will be able to maintain its relevance for students. Additionally, the school librarian will act as a guide for students as they explore the worlds of reading, imagination and academic achievements.
\end{abstract}

Keywords: Kazakhstan, Nazarbayev Intellectual School, NIS, Functional Literacy, Reading, Methods, Teacher-Librarian, Library Activities, School Library Role, Reading Projects, Reading Promotion, Research Skills

\section{FROM SCHOOL LIBRARY TO INFORMATION MEDIA CENTER}

The modern school library is the informational and intellectual center of the school, a platform which allows for a more comprehensive approach to educating students and a world of creativity which aids students in their manifestation as an individual.

Within the framework of the state program "20 Intellectual Schools", Nazarbayev Intellectual Schools and their respective libraries were founded in the Republic of Kazakhstan.

"The Intellectual Schools were designed as an experimental platform for the development, monitoring, research, analysis, introduction and implementation of modern models of educational programs. These programs are divided into levels, from: elementary school (including pre-school education and training), primary school to high school. To then introduce the modern forms of governance in education, and to develop academic freedom and autonomy for the implementation of innovative educational programs and research projects, on January 19, 2011, by the Law of the Republic of Kazakhstan and through recognition of Nazarbayev University, the "Nazarbayev Intellectual Schools" and "Nazarbayev Fund" was adopted into practice." 
The given status implies a right for the schools to approve their own educational curricula, establish requirements for entrance exams, monitor ongoing student progress, and work toward interim and final certification as well as other goals. The principle of academic freedom accelerates the development and successful implementation of new programs for the modernization of secondary education." (Nazarbayev Intellectual Schools, n.d.).

The libraries of NIS schools face the difficult task of moving away from established stereotypes and raising the purpose and function of the library to a modern, international level. The main goals of the libraries are to create an enabling environment for the development of intellectual potential and research skills of students, implement new information technologies, integrate informational literacy and academic studies, provide professional development for NIS librarians, and conform to an international model for school libraries.

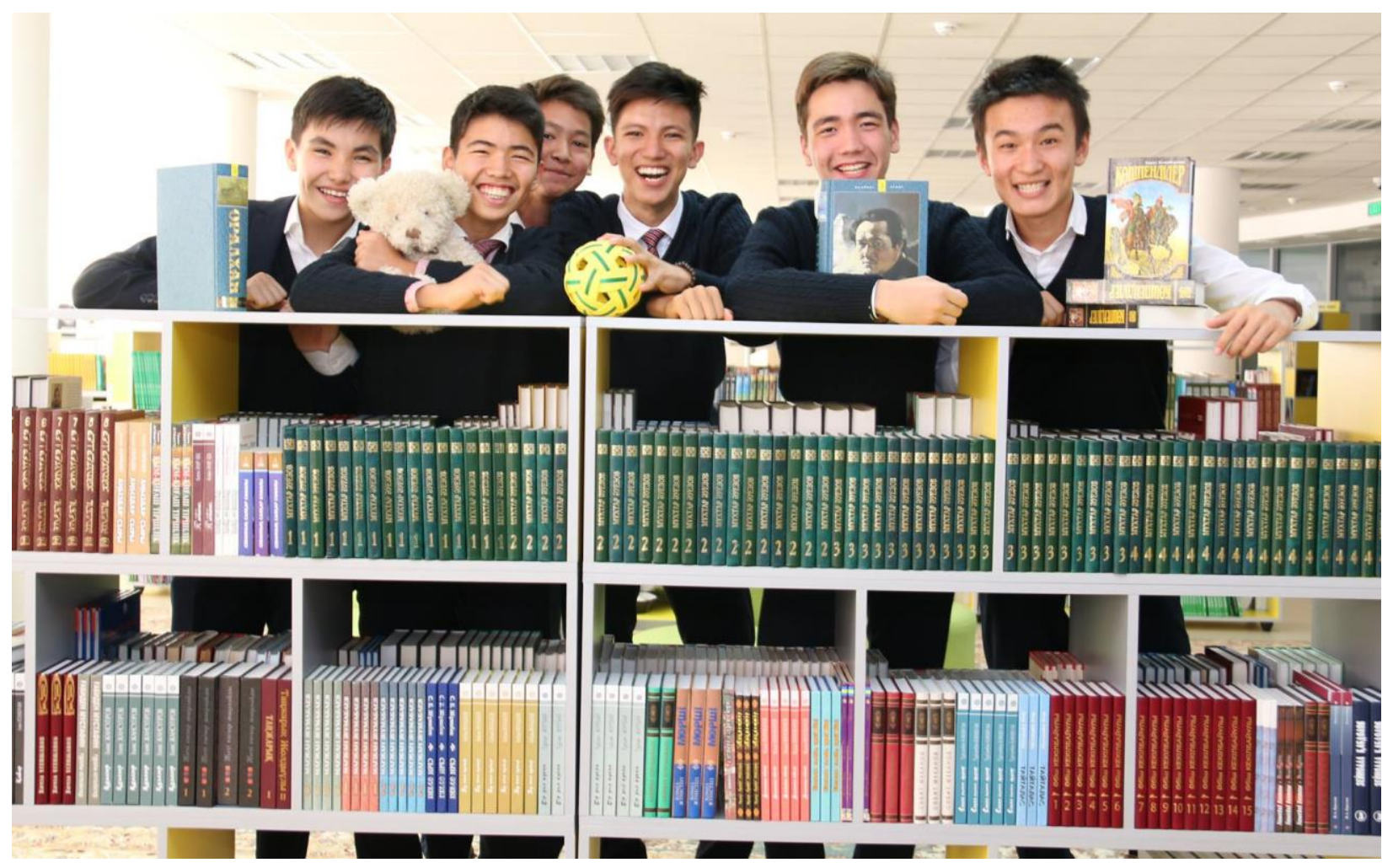

According to the State Program for the Development of Education of the Republic of Kazakhstan for 2011-2020, a program, which aims to form intellectually, physically and spiritually, developed citizens and satisfy the country's educational needs through effective schooling, one of the indicators of success for this process is the formation of functional literacy of students.

\section{THE FORMATION OF FUNCTIONAL LITERACY AND READING SKILLS IN STUDENTS}

Increasing reading literacy is one of the urgent tasks not only for Kazakhstan, but also for the entire world community, as evidenced by the results of a study of the Program for International Student Assessment (PISA) which compared 15-year-old students from all over the world. In 2009, according to the reading test results from 65 countries, Kazakh students took 62 place. To address this problem, various methods are used in the libraries of Nazarbayev Intellectual Schools, including: "Keyword Hexagon," article summaries, graphical organizers, "Darkened poetry" and more. These methods were learned at advanced training courses given by universities in the United States of America, Singapore and Finland as well as through participation in the international conferences of IFLA and IASL. Additionally, 
seminars and workshops were annually held at NIS schools by inviting international library experts from South Korea, Malaysia, and Russia. These courses allowed for NIS libraries to gain different perspectives through the experiences of international librarians and to develop their own potential as school librarians. Upon completion of such trainings, teacher-librarians of Nazarbayev Intellectual schools actively share and present the gained knowledge throughout the country. In order to improve public school libraries and help them to implement new methods of developing reading skills and functional literacy, during the period from 2013-2017, 225 training seminars were conducted for 3,585 librarians of Kazakhstan's public schools.

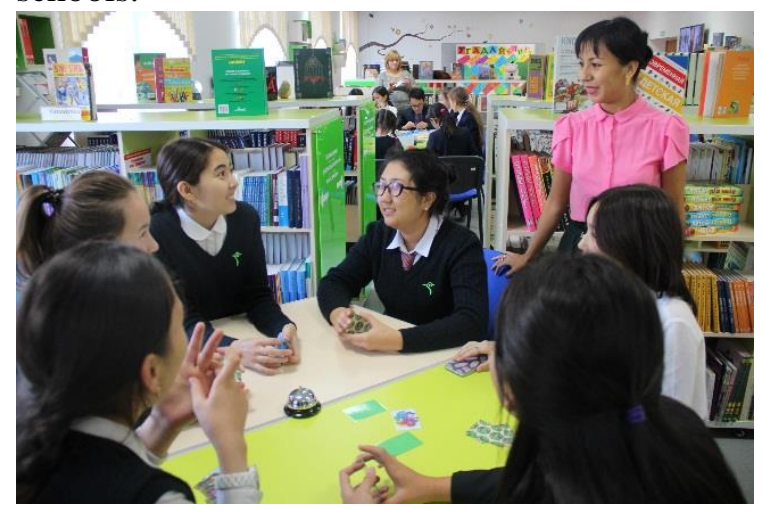

To promote reading in the school library, active play methods of working with the book are very relevant: "Find the Title of the Book," "Guess the book," "Books Conquer the World," "Book Bingo," "Book Dingo" and "Book Search" are some of the activities used. By participating in such activities, students receive a sense of satisfaction and motivation as well as a freedom to express themselves. In order to popularize books and encourage students to read, different types of library activities are held, such as: "BiblioSumerki," "Catch Reading for Lunch," "Library without Borders," "Book Slam," "Teacher-Doubler,"

"Sweet Quiz," and "1,2,3" among others. Such activities provide an opportunity for teacher-librarians to study the psychological characteristics of students, develop their communication skills and identify any creative inclinations they may have.

\section{Actions and Projects to Attract Students to Reading}

Across the libraries of Nazarbayev Intellectual Schools there are reading projects, including: "Booksrossing," "100 Books Recommended for Students of NIS Schools," DEAR, READx, "Reading time," "Book Surprise" and more. The main goals and objectives of the projects are to: develop reading skills and the literacy of students, form skills for functional reading, develop critical thinking and promote books.

In 2012, the Nazarbaev Intellectual Schools Network launched the "Bookcrossing" reading action for the first time. This is an annual social event where books are given to the libraries of rural schools and orphanages. The project takes place on the eve of the Day of the First President on December $1^{\text {st }}$, and on Independence Day of the Republic of Kazakhstan, December $16^{\text {th }}$, in all NIS schools. During the period from 2013-2016, the total number of transferred books was 24,412 copies. Each year, the "Bookcrossing" becomes more popular, acquires relevance and importance, and continues to spread to more public and

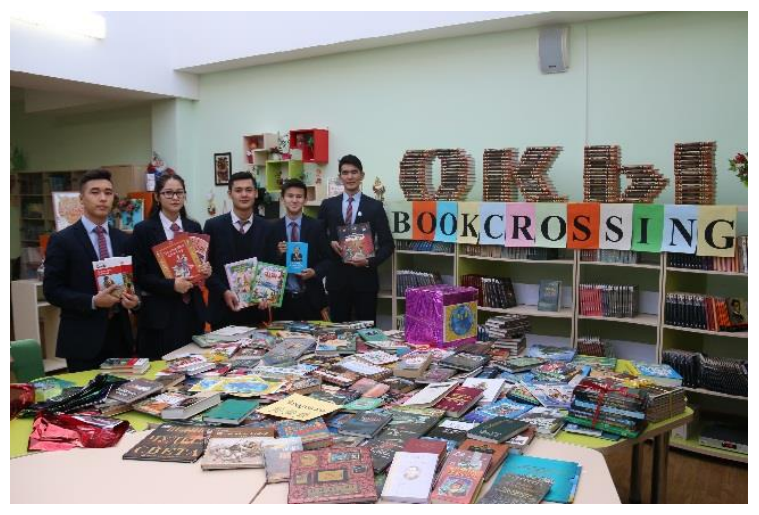
rural schools across every region of the republic. This project has had a positive effect on attracting the public to reading.

In the Nazarbayev Intellectual Schools one of the most successful and long-lasting programs to promote reading, the "Book Start" project, has begun. The project, which originated in England in 1992, has been implemented in such countries as Belgium, Germany, Scotland, Sweden, Denmark, Japan and South Korea. The purpose of the "Book Start" project is to involve parents in developing children's interest in books and reading and establish close relationships between parents and toddlers by reading illustrated books. 
Both the "Bookcrossing" and "Book Start" projects are charitable initiatives, wherein students and teachers of Intellectual schools give personal books to another member of the school community. As such, planning and preparation for these projects takes effort and a significant amount of time. Librarians organize the collection of books, the advertising of projects and the monitoring of shared opinions from the school community. Representatives of the school's self-government, which includes students and their supervisors, are of great assistance in these projects.

One of the forms and methods of the book promotion and reading support is the "Reading Time" project. This is a daily, 20-minute break, during which all students and school staff stop what they are doing and read books. Reading Time is a great way to work out the habit of reading for students, making reading books a daily necessity. The daily practice of the "Reading Time" project takes place in all of the Intellectual Schools at different times, with each school choosing the best time according to their needs and schedule. During this time, all staff and students postpone any activity and read for 20 minutes, and so many schools opted for a long break. Through the implementation of "Reading Time," students realized that they could read the books that they did not have time to read at other times, which encouraged personal choices for students and staff alike.

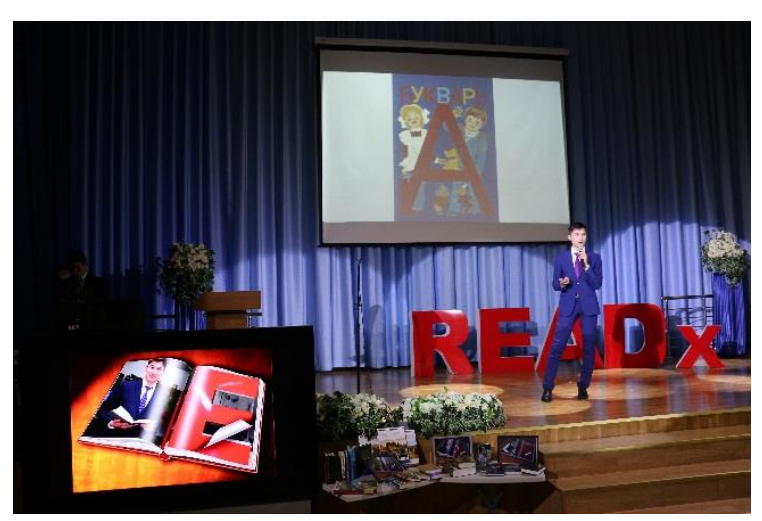

A particularly interesting project, which received great success upon introduction to Nazarbayev Intellectual Schools, was the READx Project. The READx project is an inspiring presentation about discoveries in reading. Once a month, in the assembly hall a large audience gathers in which all students and school staff are invited to listen to the speeches of 5 READx participants. Anyone who is part of the school community can be a speaker for the project; for example, a teacher, a student, a parent or an administrator, as long as they are ready to share their opinion of the book they have read. The READx project encourages students to read books, broadens their reading interests, creates the attractive image of a reading teenager in the eyes of their peers, successfully supports reading lifelong reading habits and develops public speaking skills.

The civil education of the younger generation is one of the most important tasks for an NIS school. Throughout the network of Nazarbayev Intellectual Schools, the MEMORO project has started to run. The project, which was founded in Italy, operates in 17 countries, including: Spain, Catalonia, Germany, Japan, France, the USA and South Korea. The MEMORO NIS project is an opportunity for the younger generation to become acquainted with the history of their country. Through each separate story, there is a general picture about the life for the older generation. The "Collectors of Memories" are NIS students who shoot videos and get a chance to meet with the people of older generation. Creating the video of memories then becomes a vehicle for mutual understanding and communication between generations.

As for the project "100 Books Recommended for Students of Nazarbayev Intellectual Schools," wellknown literary works in Kazakh and Russian as well as foreign classics and masterpieces of world literature are compiled in list form for students. The project is aimed at supporting trilingual learning, studying history and fostering tolerance for other cultures through reading literature in foreign languages. Promotion of the project during the academic year is carried out through a variety of activities, fore example: creative and literary evenings, reading clubs, exhibitions, games, quizzes, school theaters and video reviews. At the end of the

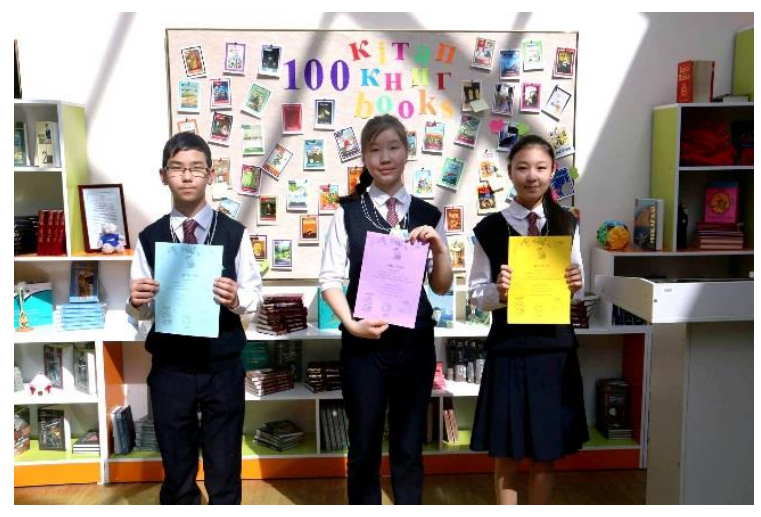
school year, according to the results of all the activities held, the most active readers are awarded with the 
"Reading Diplomas." The implementation of such projects is now spreading to other pilot and innovative schools.

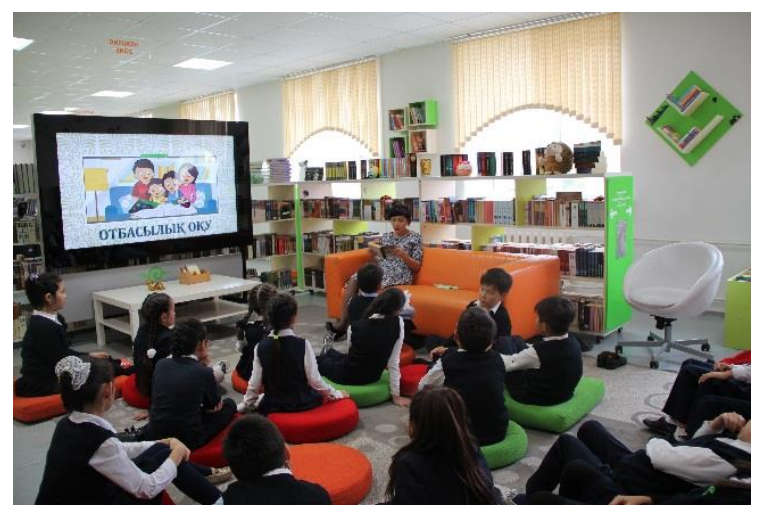

To develop a culture of reading, leisure activities are promoted for NIS students such as reading clubs, creative clubs, and family reading clubs. The involvement of parents in the work of reading clubs has become a challenge for school librarians. Initially, family reading clubs were created for the primary schools, at which each invited parent read and discussed the book with students. This practice had a warm reception from the children and it encouraged them to invite their parents to reading clubs with greater frequency. Each student wanted to see his or her parent as the next adult to read a book for the enjoyment of the class. Following the great success of the project at the primary level, parents became frequent guests in reading clubs for secondary and high school students. Involving students in the clubs allows them to organize their leisure time at a new level, to promote their self-realization and to inspire creativity.

A Nazarbayev Intellectual School library is not only a part of the educational process and directs leisure reading, but is also the resource base and information center of the school. In order to keep members of the school community informed, organize and maintain professional contacts, share the work of the library and reach a large audience of users, the libraries of Nazarbayev Intellectual Schools have created Web sites as well as social networking pages like Facebook and VKontakte. The use of interactive technologies in the work of the school library increases the effectiveness of the pedagogical activity of the school librarian. Librarians, using the Web 2.0 services, create incredibly beautiful and bright virtual exhibitions of books on various topics

Currently, Intellectual School libraries are informational and cultural centers actively involved in the life of schools, by organizing information as well training and leisure activities for all types of library users. Through the involvement of students, parents and teachers, the libraries have earned a reputation for being an accessible and approachable center of learning within the NIS schools.

The support and guidance of reading is a strategically important element of the educational process, a tool for increasing intellectual potential as well as creative and social development in students. In this century of new information technologies, when significant changes in education are sure to come, the work of the teacher-librarians of Nazarbayev Intellectual Schools is aimed at forming reading skills, functional literacy, research skills and critical thinking. This will be done through various forms and methods, to form a moral, intellectual, and literate multicultural citizen who is also a patriot of their country and ready for lifelong learning.

\section{REFERENCES}

Nazarbayev Intellectual Schools. (n.d.). History. Retrieved May, 2017 from http://www.nis.edu.kz/en/about/history 